\title{
Immune PID controller based on differential evolution algorithm for heart rate regulation
}

\author{
Tariq Tashan ${ }^{1}$, Ekhlas Hameed Karam ${ }^{2}$ and Eman Falah Mohsin ${ }^{3 *}$ \\ Lecturer, Department of the Electrical Engineering, Mustansiriyah University, Baghdad, Iraq ${ }^{1}$ \\ Assistant Professor, Department of Computer Science, Mustansiriyah University, Baghdad, Iraq ${ }^{2}$ \\ MS Student, Department of Computer Engineering, Mustansiriyah University, Baghdad, Iraq $^{3}$ \\ Received: 20-December-2018; Revised: 31-January-2019; Accepted: 21-February-2019 \\ (C)2019 Tariq Tashan et al. This is an open access article distributed under the Creative Commons Attribution (CC BY) License, \\ which permits unrestricted use, distribution, and reproduction in any medium, provided the original work is properly cited.
}

\begin{abstract}
This paper presents different structures of immune proportional-integral-derivative (PID) control system, to regulate the heart rate. It is based on Yanagihara, Noma, and Irisawa (YNI) model that represent the mathematical model of the heart. Three structure designs have been proposed to emphasize the optimality in the control process. In this work differential evolution $(\mathrm{DE})$ algorithm is considered to optimize the controller parameters. The performance of the proposed three controllers has been compared to traditional PID methods. The comparison results show best improvement when using the proposed structure-III with 0\% maximum overshoot, a reduction of 98.9\%, 96.8\% and $30.8 \%$ in rising time, settling time, and steady state error respectively.
\end{abstract}

\section{Keywords}

Immune system, Proportional-integral-derivative (PID) controller, Differential evolution, Human heart, YNI model.

\section{Introduction}

Cardiovascular diseases constitute the major causes of death worldwide, especially in the developed countries. Two famous cardiac diseases are bradycardia and tachycardia, which results in shortness of breath, fainting and in sometimes death $[1,2]$. Bradycardia is defined as a heart rate less than $60 \mathrm{bpm}$. Its symptoms become clear when the rate drops below $50 \mathrm{bpm}$, while tachycardia is defined as a heart rate greater than $120 \mathrm{bpm} \mathrm{[3].} \mathrm{There} \mathrm{are}$ various solutions to treat heart diseases, from the simplest, such as diet to sophisticated solutions such as heart transplantation. The fast development in technology offers a solution in between, which is more efficient than the diet, yet less risky than heart transplantation. This can be achieved by using an electronic device that observes heart functionality and compensate any disorder. In the last years, several researchers developed the control system to regulate the heartbeat like fractional-order PID (FOPID) controller which is suggested by Arunachalam et al. [4] for cardiac pacemaker based on the Ziegler-Nichols tuning method.

*Author for correspondence
The result was found that, the FOPID controller was better in terms of overshoot, settling time, and rising time than comparative controller. Aabid et al. [5] use PID controller, which its coefficients are tuned by ant colony optimization (ACO) algorithm in order to control and improve the hydro-electromechanical (HEM) mathematical model of the human heart that based on YNI model. Aghdam et al. [6] suggest a new intelligent control algorithm using adaptive neuro-fuzzy inference system (ANFIS) for cardiac pacemakers based on various states of patient blood pressure, sex, and age; various states of the body exercising, walking, and the rest. Karar [7] developed a new adaptive backstepping control based on radial basis function to improve the performance of dual sensor pacemakers to regulate heart rate. He tested the suggested controller by using pre-determined data for different patients heart rate [7]. Castroa and Malathi [8] designed a backpropagation neural network (BPNN) based on the conventional PID controller, to regulate the heart rate. The coefficients of a PID tuned by Zeigler-Nichols represents the weights of the output layer in BPNN. Elnaggar et al. [9] designed a fuzzy-proportional-derivative (FPD) controller of a cardiac pacemaker. The fuzzy controller, which is Mamdani type considered as an integration in a conventional PID. 
In this paper, the concept of the body's immune system as a controller with PID is used to regulate the arrhythmia that happened in heart rate, based on the DE to tune its parameters. To achieve these goals, since the 1960s, different mathematical models of the human-heart have been investigated using the physical models of real systems as reference scales [10]. One of them is the YNI model which considered here.

The rest of this paper is outlined as follows: section 2 presents the mathematical model of a heart. Section 3 describes the immune system details, while section 4 illustrates the DE algorithm. Section 5 explains the design of proposed immune-PID structures controller. Section 6 addresses the simulation results and analysis of the proposed controllers, and section 7 provides the final conclusion.

\section{Mathematical model of a heart}

There are different mathematical models that represent the human heart, such as Nobel model [11] which presents a representation of the Purkinje fiber cell's action potential. Mcallister, Noble, and Tsien (MNT) model offers an improved model for the Purkinje fiber's action potential [12]. Beeler and Reuter [13] present the first model of ventricular myocardial cell's electrical behaviour. The YNI model is one of the earliest models of Sino Atrial (SA) nodal cell's action potential behaviour [2, 14, 15]. All these models are of Hodgkin-Huxley $(\mathrm{HH})$ type, which expressed in terms of ionic currents and conductance.

In this paper, the SA model is used to represent the mathematical model of the human heart. The YNI model can simulate the heart's action potentials accurately. YNI model is an HH type, which is based on voltage clamp data. Where the relationship between voltage and current is considered and simulates the spontaneous action potential. The YNI model has four types of time-dependent currents (delayed inward current activated by hyperpolarization $I_{h}$, slow inward current $I_{s}$, potassium current $I_{k}$, and sodium current $I_{N a}$ ), and one time-independent current is the leakage current $I_{l}$. The equivalent electrical circuit model of a cell membrane can be represented by a capastor and variable resistor as stated in [15].
The unit of the trans-membrane current is $\mu \mathrm{A} / \mathrm{cm}^{2}$.

$\mathrm{C}_{\mathrm{m}} \frac{\mathrm{dV}}{\mathrm{dt}}+\mathrm{I}_{\mathrm{h}}+\mathrm{I}_{\mathrm{s}}+\mathrm{I}_{\mathrm{l}}+\mathrm{I}_{\mathrm{k}}+\mathrm{I}_{\mathrm{Na}}=\mathrm{I}_{\mathrm{app}}$

Where $C_{m}$ is a constant $\left(\mu F / \mathrm{cm}^{2}\right)$ refers to the cell membrane capacitance; $\mathrm{I}_{\text {app }}$ represents the external applied current.

The Equation 1 can be simplified as:

$\mathrm{C}_{\mathrm{m}} \frac{\mathrm{dV}}{\mathrm{dt}}+\mathrm{I}_{\text {ion }}=\mathrm{C}_{\mathrm{m}} \frac{\mathrm{dV}}{\mathrm{dt}}+\mathrm{C}_{\mathrm{m}} \frac{\mathrm{V}}{\mathrm{R}_{\mathrm{m}}}=\mathrm{I}_{\text {app }}$

Where $C_{m}$ and $R_{m}$ represent the capacitance and the resistance respectively of the cell membrane.

Where

$\mathrm{I}_{\mathrm{h}}=0.4 \mathrm{q}(\mathrm{V}+45)$

$I_{s}=12.5(0.05+0.95 d)(0.05+0.95 f)\left(\exp \frac{v-10}{15}-1\right)$

$\mathrm{I}_{\mathrm{l}}=0.8\left(1-\exp ^{-\frac{\mathrm{V}+60}{20}}\right)$

$\mathrm{I}_{\mathrm{k}}=0.7 \mathrm{p} \frac{\exp (0.0277(\mathrm{~V}+90))-1}{\exp (0.0277(\mathrm{~V}+40))}$

$\mathrm{I}_{\mathrm{Na}}=0.5 \mathrm{~m}^{3} \mathrm{~h}(\mathrm{~V}-30)$

$\frac{\mathrm{dw}}{\mathrm{dt}}=\alpha_{\mathrm{w}}(1-\mathrm{w})-\beta_{\mathrm{w}} \mathrm{w}$

Where $w=\{q, d, f, p, m$, or $h\}$.

The gating variables $q, d, f, p, m$, and h must satisfy the first-order differential Equation 8. Using the constants' values listed in Table 1 , constants $\alpha_{\mathrm{w}}$ and $\beta_{\mathrm{w}}$ can be obtained as shown in Equation 9.

$\alpha_{\mathrm{w}}, \beta_{\mathrm{w}}=\frac{\mathrm{C}_{1} \exp \left(\frac{\mathrm{V}-\mathrm{V} 0}{\mathrm{C}_{2}}\right)+\mathrm{C}_{3}(\mathrm{~V}-\mathrm{V} 0)}{1+\mathrm{C}_{4} \exp \left(\frac{\mathrm{V}-\mathrm{V} 0}{\mathrm{C}_{5}}\right)}$

The parameters $\left(\alpha_{p}, \alpha_{q}, \beta_{q}, \alpha_{d}, \beta_{f}\right)$ cannot be calculated from Equation 9, therefore, they are calculated by:

$$
\begin{aligned}
& \alpha_{\mathrm{p}}=9 \times 10^{-3} \frac{1}{1+\exp \left(-\frac{\mathrm{V}+3.8}{9.71}\right)}+6 \times 10^{-4} \\
& \alpha_{\mathrm{q}}=3.4 \times 10^{-4} \frac{(\mathrm{V}+100)}{\exp \left(\frac{\mathrm{V}+100}{4.4}\right)-1}+4.95 \times 10^{-5} \\
& \beta_{\mathrm{q}}=5 \times 10^{-4} \frac{(\mathrm{V}+40)}{1-\exp \left(-\frac{\mathrm{V}+40}{6}\right)}+8.45 \times 10^{-5} \\
& \alpha_{\mathrm{d}}=1.045 \times 10^{-2} \frac{(\mathrm{V}+35)}{1-\exp \left(-\frac{\mathrm{V}+35}{2.5}\right)}+3.125 \times \\
& 10^{-2} \frac{(\mathrm{V}+35)}{1-\exp \left(-\frac{\mathrm{V}+35}{2.5}\right)} \\
& \beta_{\mathrm{f}}=9.44 \times 10^{-4} \frac{(\mathrm{V}+60)}{1-\exp \left(-\frac{\mathrm{V}+29.5}{4.16}\right)}
\end{aligned}
$$


Table 1 Defined values of $\beta$ and $\alpha$ of YNI model [15]

\begin{tabular}{llllllll}
\hline & $\boldsymbol{\alpha}_{\mathbf{h}}$ & $\boldsymbol{\alpha}_{\mathbf{m}}$ & $\boldsymbol{\alpha}_{\mathbf{f}}$ & $\boldsymbol{\beta}_{\mathbf{p}}$ & $\boldsymbol{\beta}_{\mathbf{h}}$ & $\boldsymbol{\beta}_{\mathbf{d}}$ & $\boldsymbol{\beta}_{\mathbf{m}}$ \\
\hline $\mathbf{C}_{\mathbf{1}}$ & $1.209 \times 10^{-3}$ & 0 & 0 & 0 & 1 & 0 & -10 \\
\hline $\mathbf{C}_{\mathbf{2}}$ & -6.534 & - & - & - & $\infty$ & - & -17.8 \\
\hline $\mathbf{C}_{\mathbf{3}}$ & 0 & 1 & $-3.55 \times 10^{-4}$ & $-2.25 \times 10^{-4}$ & 0 & $-4.21 \times 10^{-3}$ & 0 \\
\hline $\mathbf{C}_{\mathbf{4}}$ & 0 & -1 & -1 & -1 & 1 & -1 & 0 \\
\hline $\mathbf{C}_{\mathbf{5}}$ & - & -10 & 5.633 & 13.3 & -10 & 2.5 & - \\
\hline $\mathbf{V}_{\mathbf{0}}$ & -20 & -37 & -20 & -40 & -30 & 5 & -62 \\
\hline
\end{tabular}

\section{Immune system}

A natural immune system is a detection system distributed throughout the body with many functional components in strategic positions. Identifying all cells within the body and classifying them as self-or non-subjective is considered the primary function of the immune system. Non-subjective-cells are also classified in order to motivate suitable protection mechanisms. Through evolution, the immune system learns to recognize the foreign antigens (such as viruses or bacteria) from the cells or molecules of the body. The basic type of immune cells is the lymphocyte, which forms the immune response, and includes adaptability, specificity, the attributes of diversity, and memory. The main two types of lymphocytes are the B-cells and the T-cells. The Bcells are generated in the bone marrows, a human body contained $10{ }^{7}$ various types of B-cells, and each one produces antibodies in the form of ' $\mathrm{Y}$ ' from their surfaces with various chemical structures. The $\mathrm{T}$-cells are generated from the thymus. T-cells are classified into suppressor T-cells $\left(T_{s}\right)$ and helper Tcells $\left(T_{H}\right)$ [16]. When the cell obtains a signal from the antigen, it transmits the information to $T_{H}$ and $T_{S}$, and then the B-cell produces corresponding antibodies, to resist the antigen with the stimulation by $T_{H}$ and $T_{S}$ [17]. According to this mechanism of immunity feedback control, the B-cells consistency of the $\mathrm{k}^{\text {th }}$ generation can be obtained as follows:

$B(k)=T_{H}(k)-T_{S}(k)$

$T_{H}(k)=K_{1} \delta(k)$

$T_{S}(k)=K_{2}\{f[\Delta B(k-d)]\} \delta(k)$

Where $f$ is a nonlinear function which refers to the interaction between the antigen and antibody which elicits from B-cells, $\delta(k)$ is the $\mathrm{k}^{\text {th }}$ generation antigen consistency, $K_{1}$ and $K_{2}$ represents the helper gene and the suppressor gene respectively, $B(k)$ is the consistency B-cells, and the change of consistency in B-cell represented by $\Delta B(k-d)=B(k-d)-$ $B(k-d-1)$ where the time delay of immune response represented by $\mathrm{d}$.

From Equation 15-17, the relationship between the B-cell's consistency and the antigen, can be written as:
$B(k)=K_{1}\{1-\eta f[\Delta B(k-d)]\} \delta(k)$

Where $\eta$ is the proportional coefficient between $T_{S}$ and $T_{H}, \eta=K_{2} / K_{1}$. The right immune response must be stable, and has fast reaction to remove all attacking antigens. In addition, a high antibody consistency must be controlled, since it may harm the body. In a control system of dynamic regulation, the deviation must be slaked to ensure the stability of the system; this is in agreement with the immune system target.

\section{Differential evolution algorithm}

DE is one of metaheuristic optimisation techniques, which modifies iteratively a population of candidate solutions, to make it converge to an optimum solution [18-20]. The key parameters of DE are: D- problem dimension (refers to the number of tuned parameters in the immune $\left(k_{l}\right.$ and $\left.\eta\right)$ or $\left(k_{p}, k_{i}\right.$, and $\left.k_{d}\right)$ in the case of PID), GEN-the number of generation (stopping condition), NP-the population size, F-the weight applied to random differential (scaling factor), and CR-the crossover constant. The last three parameters are called control parameters. Storn [18] suggests several rules to select these parameters. The DE can be described by the following steps:

Step 1: Initialize the parameters $D, G E N, N P, C R, F$, $L, H$-boundary constraints ( $\mathrm{L}=$ Lower and $\mathrm{H}=$ Higher) Initialize population $\quad X_{i j} \leftarrow L+(L-H)$. random $_{i j}\left(\mathrm{)}\right.$ and evaluate fitness Fit $_{j} \leftarrow f\left(X_{j}\right)$

Where $i=1, \ldots, D j=1, \ldots, N P$

for $g=1$ to $G E N$ do

for $j=1$ to $N P$ do

Step 2: select random indices $r_{1,2,3} \in[1, \ldots, N P], r_{1}$ $\neq r_{2} \neq r_{3} \neq j$

Step 3: generate trial individual vector $U_{j}$

-Generate the mutant vector $v_{j}$

$v_{j}^{g}=X_{r 3}^{g}+F \cdot\left(X_{r 1}^{g}-X_{r 2}^{g}\right)$

-Apply the crossover operator $U_{j}$

$U_{j}^{g}=\left\{\begin{array}{lr}v_{j}^{g} & \text { if }(\text { rand }[0,1] \leq C R) \\ X_{j}^{g} & \text { Otherwise }\end{array}\right.$

- Verify boundary constraints

if $\left(U_{j} \neq[L, H]\right) U_{j} \leftarrow L+(L-H) \cdot \operatorname{random}_{j}()$ 


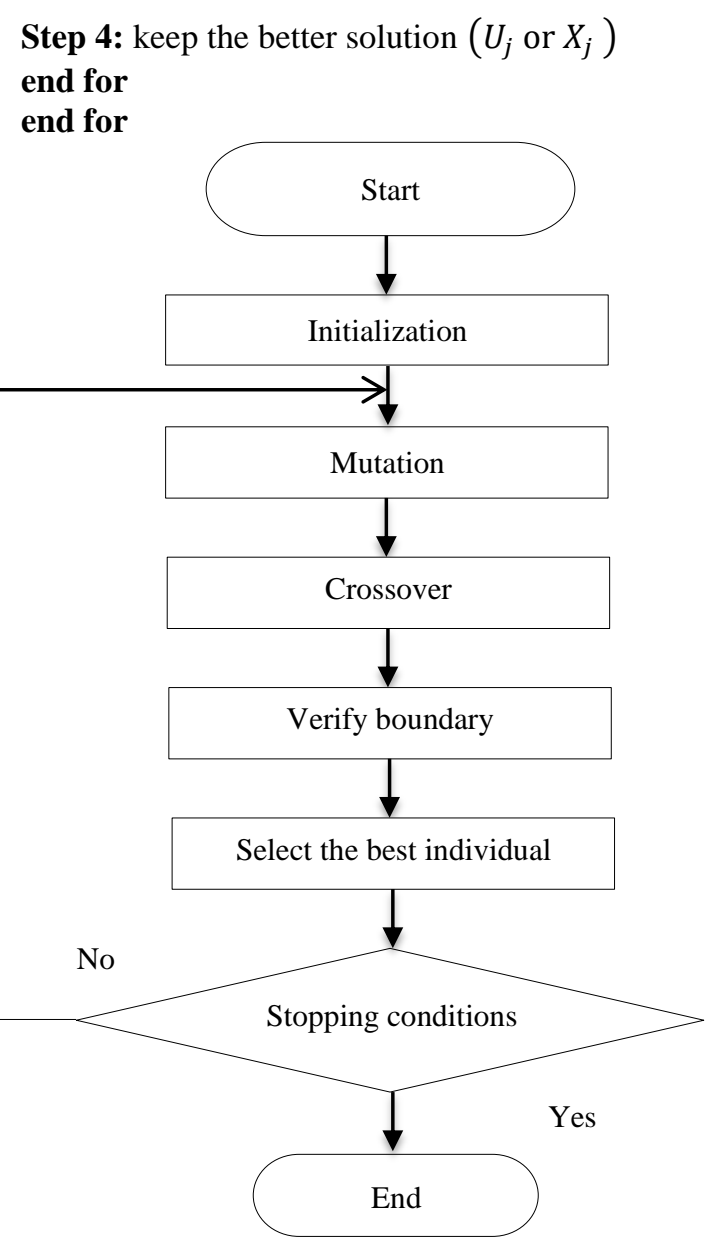

Figure 1 DE algorithm

\section{Proposed algorithm}

In this paper three structures of Immune-PID controller is proposed to regulate the case of the arrhythmia. The parameters of the PID and Immune blocks are tuned using the DE algorithm. The three structures are explained in following subsections.
Assume the error $e(k)$ referred to the amount of antigen $\delta(k)$, and the input of the controller $u(k)$ will be the total motivation that is accepted by the B-cells. Then the feedback control system will be represented as:

$$
\begin{array}{r}
u(k)=K\{1-\eta f[\Delta u(k-d)]\} e(k) \\
=K_{I} e(k)
\end{array}
$$

Where $(1-\eta f[\Delta u(k-d)])=K_{I}$ is the immune controller's proportional gain, $\eta=K_{2} / K_{1}$ is the gene that controls the amount of $K_{I}$, and $f$ is a nonlinear function.

A nonlinear function is selected here as T-cell's regulate action-function, dependent on the influence of the antigen consistency on antibody in immune response.

$\mathrm{f}(x)=1-\frac{2}{1+\exp (-c x)} \quad \mathrm{c}>0$,

Where the range of $f(\mathrm{x})$ is $[-1,1]$, the active region of $x$ is determined by $c$ value.

It can be written the immune controller's output as:

$$
\begin{gathered}
u(k)=K\left\{1-\eta\left(1-\frac{2}{1+\exp (-c x)}\right)\right\} e(k) \\
=K_{I} e(k)
\end{gathered}
$$

The immune controller is a nonlinear proportional $(\mathrm{P})$ controller. Therefore, it is not robust against noise and error caused by nonlinear disturbance. To overcome this problem and improve the performance of that system, the immune $\mathrm{P}$ controller is required to be merged with traditional PID [16, 17, 21-23], as shown in Figure 2 and Equation 22 shows the controller output for this structure.

$$
\begin{aligned}
& u(k)=k_{I} \times k_{p}\left[1+\frac{k_{i}}{1-z^{-1}}+k_{d}\left(1-z^{-1}\right)\right] e(k) \\
& =k_{I P}\left[1+\frac{k_{i}}{1-z^{-1}}+k_{d}\left(1-z^{-1}\right)\right] e(k)
\end{aligned}
$$

Where $k_{I P}$ represents proportional gain.

\subsection{Immune PID structure I}



Figure 2 The immune PID controller block diagram structure I 


\subsection{Immune PID structure II}

The block diagram of this structure is shown in Figure 3, where the PID is connected in parallel with the immune controller and the input for PID and immune controller is the error signal $e(\mathrm{k})$. The control law for this structure is:

$$
\begin{aligned}
& u(k)=k_{I} e(k)+k_{p}\left[1+\frac{k_{i}}{1-z^{-1}}+k_{d}(1-\right. \\
& \left.\left.z^{-1}\right)\right] e(k)
\end{aligned}
$$

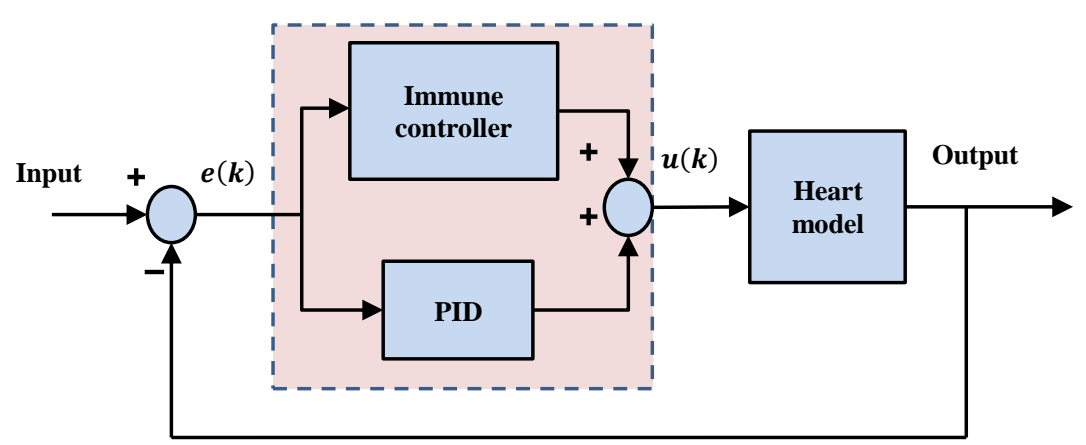

Figure 3 The immune PID controller block diagram structure II

\subsection{Immune PID structure III}

Figure 4 illustrate the block diagram for this structure, where the PID is multiplied by the immune controller and the error signal is consider as input signal for these two controllers. The control law for this structure is:

$$
\begin{aligned}
& u(k)=k_{I} e(k) \times k_{p}\left[1+\frac{k_{i}}{1-z^{-1}}+k_{d}(1-\right. \\
& \left.\left.z^{-1}\right)\right] e(k) .
\end{aligned}
$$

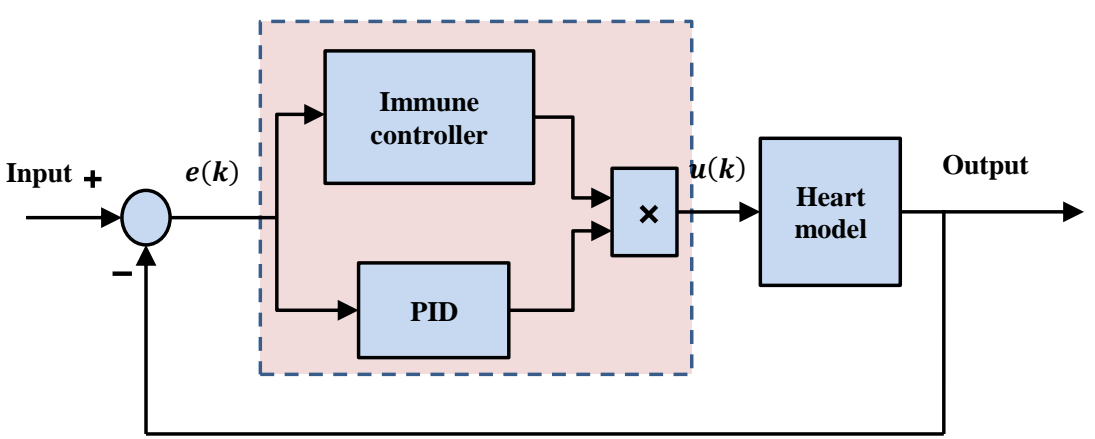

Figure 4 The immune PID controller block diagram structure III

\section{Simulation results and analysis}

The simulation results of the proposed controllers based on the DE algorithm for controlling YNI heart rate model have been presented in this section for the heart rate of $60 \mathrm{bpm}$ (older person) and $70 \mathrm{bpm}$ (normal adult). The YNI model response to the two cases without controller is shown in Figure 5 and Figure 6 respectively. These results show that the actual (output) heart rate has reached the desired rate very fast (small settling time $\mathrm{t}_{\mathrm{s}}$ ) but there is an error in the steady state in both cases $(60 \mathrm{bpm}$ and 70 $\mathrm{bpm})$. Therefore the proposed controller is used based on DE algorithm.

The DE algorithm parameters are considered here are listed in Table 2. The optimal controller parameters for classical discrete PID and immune-PID structures obtained by the DE algorithm are listed in Table 3. 
Tariq Tashan et al.

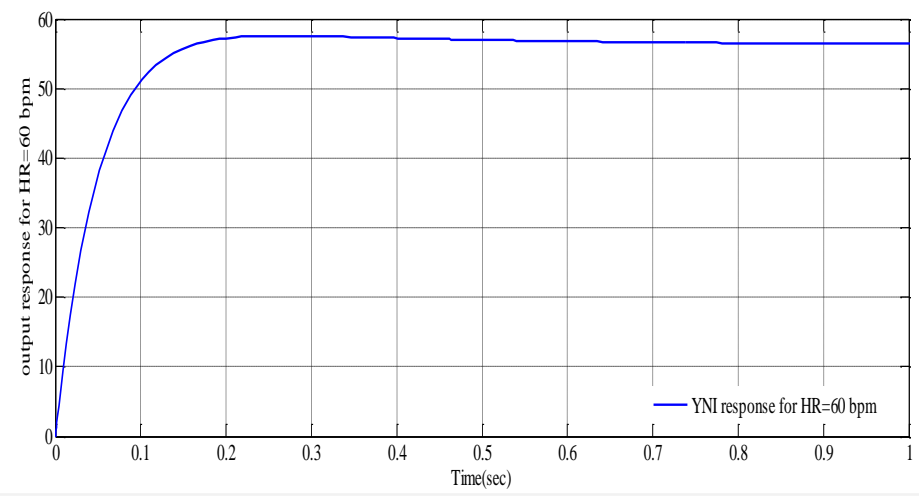

Figure 5 The YNI response for heart rate $(\mathrm{HR})=60 \mathrm{bpm}$

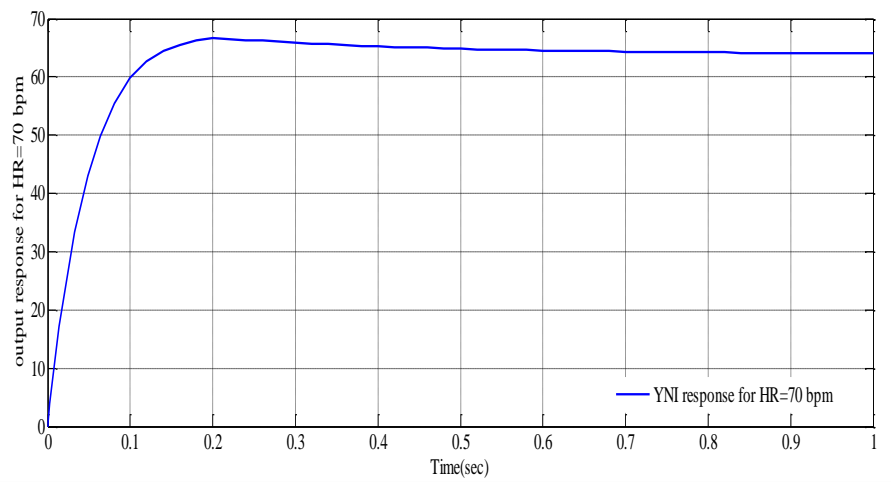

Figure 6 The YNI response for heart rate $(\mathrm{HR})=70 \mathrm{bpm}$

Table 2 The parameters that are used in DE algorithm

\begin{tabular}{ll}
\hline DE parameters & Value \\
\hline Number of tuned parameters (D) & 5 \\
Population size (NP) & 15 \\
Crossover constant (CR) & 0.6 \\
Mutation constant (F) & 0.85 \\
Number of generations (GEN) & 20 \\
\hline
\end{tabular}

Table 3 Optimal controller parameters

\begin{tabular}{lllllll}
\hline Controller & $\mathbf{k}_{\mathbf{p}}$ & $\mathbf{k}_{\mathbf{i}}$ & $\mathbf{k}_{\mathbf{d}}$ & $\mathbf{K}_{\mathbf{1}}$ & $\mathbf{\eta}$ & $\mathbf{c}$ \\
\hline PID & 3.6080 & 6.6867 & 0.0026 & --- & --- & 0.4634 \\
Immune-PID1 & 2.6781 & 7.2447 & 0.000299 & 9.6190 & 0.5 & 0.5 \\
Immune-PID2 & 5.2337 & 8.8503 & 0.0039 & 4.1499 & 0.0156 & 0.5 \\
Immune-PID3 & 2.3853 & 9.0849 & 0.000012 & 9.354 & 0.606 & 0.5 \\
\hline
\end{tabular}

The simulation response of YNI model after regulated it by the proposed controllers (immune PID with three structures) in addition to optimal PID (which also tuned by the DE algorithm as illustrated in Table 3) are shown in Figure 7 and Figure 8 respectively.
It can be noticed from Figure 7 and Figure 8 that all the controller satisfies the design requirement by making the cardiac system follows the desired heart rate with small steady state error $\left(e_{. s . s}\right)$, settling time $\left(t_{s}\right)$, rise time $\left(t_{r}\right)$ and overshoot $\left(M_{p}\right)$ as shown in Table 4 and Table 5 especially immune-PID structure III which has best average performance than the optimal PID, immune-PID structure I, and immunePID structure I). 




Figure 7 The response of YNI model according to the PID and immune-PID structures with HR=60 bpm

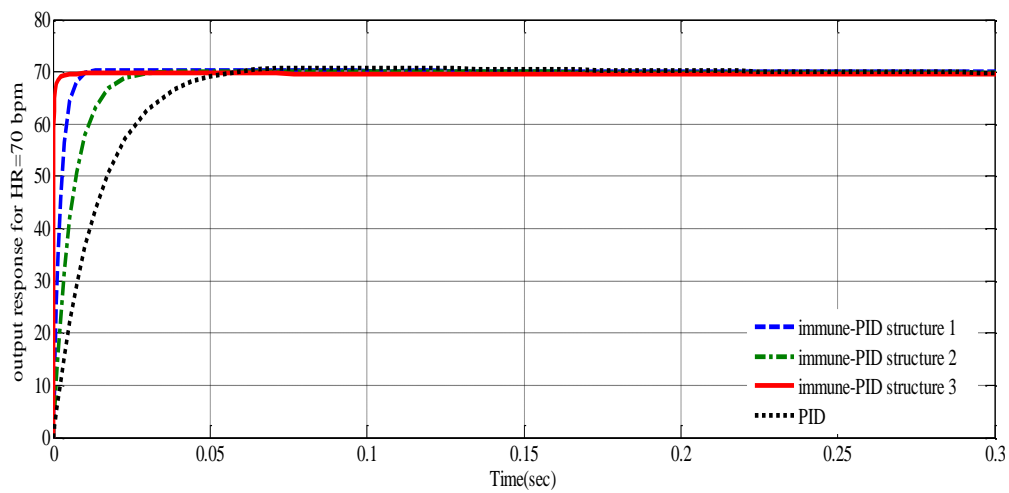

Figure 8 The response of YNI model according to the PID and immune-PID structures with HR=70 bpm

Table 4 and Table 5 also illustrates that the performance of the immune-PID-structure II is nearly

III as compared to immune-PID-structure II and similar to the performance of immune-PID-structure optimal PID.

Table 4 The evaluation parameters of simulation results for HR=60 bpm

\begin{tabular}{lllll}
\hline Controller type & $\mathbf{M}_{\mathbf{P}} \%$ & $\mathbf{t}_{\mathbf{r}}(\mathbf{s e c})$ & $\mathbf{t}_{\mathbf{s}}$ (sec) & $\mathbf{e}_{\text {s.s. }}$ \\
\hline PID & 0.92 & 0.031 & 0.0482 & -0.32 \\
Immune-PID Structure I & 0.354 & 0.0047 & 0.0081 & -0.065 \\
Immune-PID Structure II & 0.315 & 0.0126 & 0.022 & 0.31 \\
Immune-PID Structure III & 0 & 0.00034 & 0.0019 & 0.26 \\
\hline
\end{tabular}

Table 5 The evaluation parameters of simulation results for HR=70 bpm

\begin{tabular}{lllll}
\hline Controller type & $\mathbf{M}_{\mathbf{P}} \%$ & $\mathbf{t}_{\mathbf{r}}(\mathbf{s e c})$ & $\mathbf{t}_{\mathbf{s}}(\mathbf{s e c})$ & $\mathbf{e}_{\text {.s.s }}$ \\
\hline PID & 1.68 & 0.0284 & 0.0477 & 0.39 \\
Immune-PID Structure I & 0.486 & 0.0048 & 0.008 & 0.04 \\
Immune-PID Structure II & 0.6171 & 0.0124 & 0.0222 & 0.315 \\
Immune-PID Structure III & 0 & 0.00029 & 0.0015 & 0.27 \\
\hline
\end{tabular}

\section{Conclusion}

In this paper, three different structures of immunePID controller are investigated instead of the traditional discrete PID controller to regulate the heart rate. The mathematical model of heart YNI has been considered. In order to improve the characteristics of the proposed controllers, DE algorithm have been applied. The simulation results show that the immune-PID structure III outperforms the other structures. In this structure the control action of the controller is the product of the immune controller output and the PID controller output. For 
future works, we suggest implementing this controller as hardware using field programmable gate array (FPGA) and experience the suggested controller on mechanical systems such as manipulator robotic systems.

\section{Acknowledgment}

The authors thank all the colleagues in the Computer Engineering Department, College of Engineering, Mustansiriyah University, for their unlimited support.

\section{Conflicts of interest}

The authors have no conflicts of interest to declare.

\section{References}

[1] Dutta SM, Ghorbel FH. Differential hysteresis modeling of a shape memory alloy wire actuator. IEEE/ASME Transactions on Mechatronics. 2005; 10(2):189-97.

[2] Shi WV, Zhou M. Optimal single-pulse for pacemakers based on a sinoatrial model. IEEE/ASME Transactions on Mechatronics. 2013; 18(1):348-54.

[3] Anderson KP. Sudden cardiac death unresponsive to implantable defibrillator therapy: an urgent target for clinicians, industry and government. Journal of Interventional Cardiac Electrophysiology. 2005; 14(2):71-8.

[4] Arunachalam SP, Kapa S, Mulpuru SK, Friedman PA, Tolkacheva EG. Intelligent fractional-order PID heart rate controller for cardiac pacemaker. In healthcare innovation point-of-care technologies conference 2016 (pp. 105-8). IEEE.

[5] Aabid M, Elakkary A, Sefiani N. PID parameters optimization using ant-colony algorithm for human heart control. In international conference on automation and computing 2017 (pp. 1-6). IEEE.

[6] Aghdam AD, Dabanloo NJ, Sattari M, Attarodi G, Hemmati N. Design and processing of a novel algorithm using ANFIS for new generation of cardiac pacemakers. In computing in cardiology 2017 (pp. 14). IEEE.

[7] Karar ME. Robust RBF neural network-based backstepping controller for implantable cardiac pacemakers. International Journal of Adaptive Control and Signal Processing. 2018; 32(7):1040-51.

[8] Castro VJ, Malathi R. Design of advanced control strategies for cardiovascular system. Materials Today: Proceedings. 2018; 5(1):1960-6.

[9] Elnaggar MI, Ashour AS, Guo Y, El-Khobby HA, Elnaby MM. An optimized Mamdani FPD controller design of cardiac pacemaker. Health Information Science and Systems. 2019; 7(2).

[10] Cakmakci M, Ulsoy AG. Improving componentswapping modularity using bidirectional communication in networked control systems. IEEE/ASME Transactions on Mechatronics. 2009; 14(3):307-16

[11] Noble D. A modification of the Hodgkin-Huxley equations applicable to Purkinje fibre action and pacemaker potentials. The Journal of Physiology. 1962; 160(2):317-52.

[12] McAllister RE, Noble D, Tsien RW. Reconstruction of the electrical activity of cardiac Purkinje fibres. The Journal of Physiology. 1975; 251(1):1-59.

[13] Beeler GW, Reuter H. Reconstruction of the action potential of ventricular myocardial fibres. The Journal of Physiology. 1977; 268(1):177-210.

[14] Yanagihara K, Noma A, IRISAWA H. Reconstruction of sino-atrial node pacemaker potential based on the voltage clamp experiments. The Japanese Journal of Physiology. 1980; 30(6):841-57.

[15] Keener JP, Sneyd J. Mathematical Physiology. New York: Springer; 1998.

[16] Wang W, Gao XZ, Wang C. A new immune PID controller in material-level control. In international conference on natural computation 2007 (pp. 614-8). IEEE.

[17] Liu XH, Chen XH, Zheng XH, Li SP, Wang ZB. Development of a GA-fuzzy-immune PID controller with incomplete derivation for robot dexterous hand. The Scientific World Journal. 2014.

[18] Storn R. On the usage of differential evolution for function optimization. In proceedings of North American fuzzy information processing 1996 (pp. 519-23). IEEE.

[19] Vitaliy F. Differential evolution-in search of solutions. Springer Optimization and its Applications. 2006.

[20] Saad MS, Jamaluddin H, Darus IZ. PID controller tuning using evolutionary algorithms. WSEAS Transactions on Systems and Control. 2012; 7(4):13949.

[21] Ding Y, Ren L. A new fuzzy self-tuning immune feedback control system. Control and Decision. 2000; 15(4):443-6.

[22] Jiao LC, Du HF. Development and prospect of the artificial immune system. ACTA Electronica Sinica. 2003; 31(10):1540-8.

[23] Wang W, Gao XZ, Wang CH. Fuzzy immune PID controller in material-level control of preheating cylinder. In international conference on informatics and control technologies 2006 (pp. 52-5).

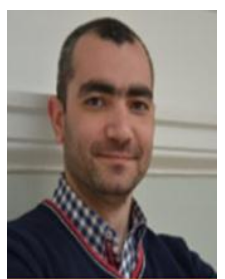

Tariq Tashan is a Lecturer at the Electrical Engineering Department, Mustansiriyah University, BaghdadIraq. He obtained his BSc in Electrical Engineering and MSc in Communication and Electronics from Mustansiriyah University. He obtained his $\mathrm{PhD}$ in Biologically Inspired Speaker Verification from Nottingham Trent University and Member of the Institution of Engineering and Technology (MIET). His research interests include Speaker Recognition, Neural Networks, and Pattern Recognition. Email: tariq.tashan@uomustansiriyah.edu.iq 
International Journal of Advanced Computer Research, Vol 9(42)

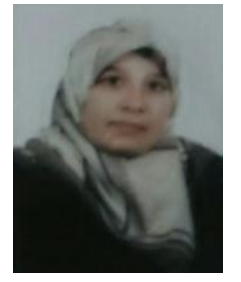

Ekhlas H. Karam received the BSc in Computer Engineering from the Mosul University, Mosul, Iraq, MSc in Control Engineering and the $\mathrm{PhD}$ in Mechatronics Engineering from University of Technology, Baghdad, Iraq. She is an Assistant Professor with the Computer Engineering Department, Mustansiriyah University, Baghdad, Iraq. Her interested areas are Robotic System, Different Controller Design, Optimization Methods, Image Processing and FPGA.

Email: ek_karam@yahoo.com

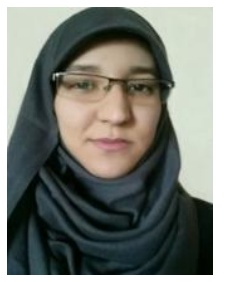

Eman Falah Mohsin received the BSc in Computer Engineering from Mustansiriyah University, Baghdad, Iraq, in 2016. Currently she is completing her M.S. study in the Department of Computer Engineering, Mustansiriyah University, Baghdad, Iraq. Her current research interests include Control Systems, Optimization Methods, and FPGA.

Email: eman.falah.94@gmail.com 